\title{
Biosimilar Issues in Cancer Management in Hong Kong
}

Lee VW', Cheng FW'

I School of Pharmacy, Chinese University of Hong Kong, Shatin, Hong Kong

\section{Background}

Since the publication of "Guidance Notes for Registration of Biosimilar Products" by the Hong Kong Department of Health in 20I6, it is expected that an increasing number of biosimilars will be registered in Hong Kong. Although biosimilars of simple proteins, such as EPO or G-CSF, have already been used in Hong Kong for few years, uncertainties for how these biosimilars shall be used in Hong Kong remains to be the challenges.

\section{Methodology}

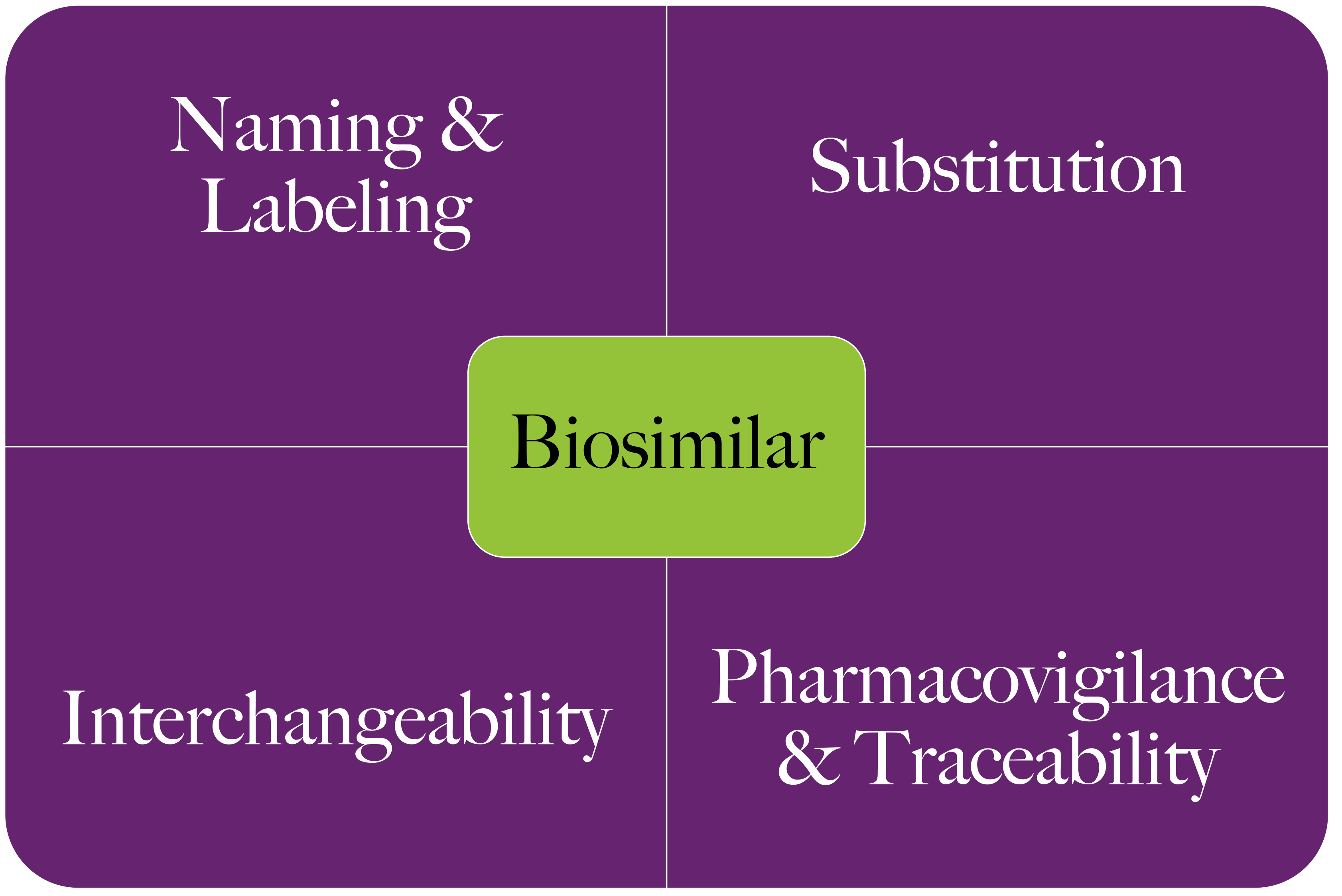

The current project used the fact disclosing approach to evaluate key issues on "Naming \& Labeling", "Substitution”, "Interchangeability" and "Pharmacovigilance \& Traceability" on biosimilars. Medication safety is vital for our patients. Their input and views are crucial for the development of guidance of biosimilar products. The implication of the WHO, EMA and FDA guidelines on the regulatory affairs of biosimilars in Hong Kong was evaluated.

\section{Results}

A lot more of the originator biological products will soon lose their patency in the next 5-IO years. Therefore, we will expect that more biosimilar products will be on the market for our patients. Biosimilar may offer alternatives with lower costs for our patients. Nevertheless, healthcare professionals and patients have limited experiences with these biosimilar products. Continuous monitoring and research to ensure positive clinical, economic and humanistic outcomes should be reinforced.

\section{Conclusion}

Multidisciplinary team efforts including patients, healthcare professionals, academics, policy makers, and healthcare regulatory authorities are important to ensure medication safety of biosimilar products.

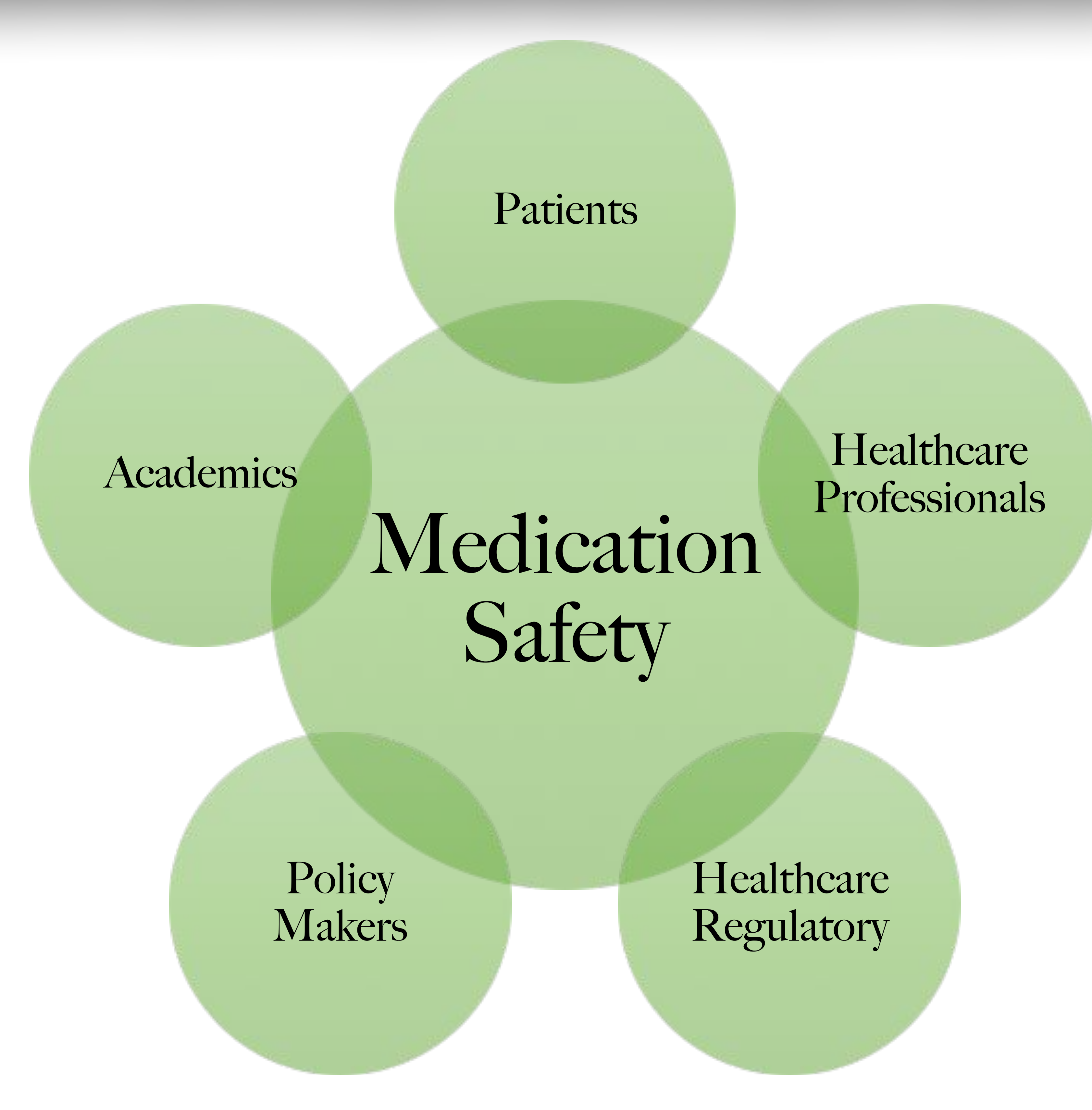

